\title{
LA NUEVA CONTRIBUCIÓN ESPECIAL PARA LAUDOS DE CONTENIDO ECONÓMICO - UN OBSTÁCULO MÁS PARA EL ARBITRAJE COLOMBIANO"
}

\author{
THE NEW SPECIAL CONTRIBUTION FOR AWARDS \\ OF ECONOMIC CONTENT-A FURDER OBSTACLE \\ FOR COLOMBIAN ARBITRATMENT
}

Juan Antonio Gaviria Gil *

\begin{abstract}
Resumen
El presente artículo analiza la contribución especial sobre laudos arbitrales de contenido económico que creó el artículo 364 de la Ley 1819 de 2016 (reforma tributaria) y explica cómo este tributo es un obstáculo más para la justicia arbitral. Para tal fin, el artículo describe
\end{abstract}

Recibido: 10 de marzo de 2017 - Aprobado: 30 de noviembre de 2017.

* Artículo inédito.

Para citar el artículo: GAVIRIA GIL, Juan Antonio. La nueva contribución especial para laudos de contenido económico - Un obstáculo más para el arbitraje colombiano. Revista del Instituto Colombiano de Derecho Procesal. No. 46. Julio - Diciembre. 2017, pp. 17-42.

** Doctor en Derecho (PhD) de American University, the Washington College of Law (Washington DC), LL.M., con énfasis en derecho de los negocios internacionales, de la misma universidad. Magíster en Economía de la Universidad EAFIT. Magíster en Derecho con énfasis en tributación de la Universidad Externado de Colombia. Especialista en Finanzas de la Universidad EAFIT. Especialista en Derecho Financiero y de los Negocios de la Universidad Pontificia Bolivariana. Abogado de la Universidad Pontificia Bolivariana. Profesor e investigador titular de tiempo completo de la Facultad de Derecho de la Universidad Pontificia Bolivariana y miembro del Grupo de Investigaciones en Derecho. Árbitro de la lista A en sociedades y derecho comercial de la Cámara de Comercio de Medellín. Contacto: juan.gaviriag@upb.edu.co 
La nueva contribución especial para laudos de contenido económico

las características más importantes de la nueva contribución parafiscal para luego explicar porque ésta no solo es inconstitucional e inconveniente sino también una muestra más de los ataques de algunas ramas del poder público contra un método alternativo de solución de conflictos que ha demostrado ser eficiente.

Palabras clave: arbitraje, contribución, equidad tributaria, laudos.

\begin{abstract}
This paper analyzes the new tax on arbitral awards granting damages that may be quantified in money that article 364 of Law 1819/2016 (the latest tax reform) established and explains why this tax is another hurdle for arbitration proceedings. In this connection, the paper describes the most important features of the new tax, explains why this is both an unconstitutional and an unsuitable measure, and indicates why it is another example of the attacks of some parts of Colombian branches against an alternative method to settle disputes that has shown to be efficient.
\end{abstract}

Key words: arbitration, contribution, tax equity, awards.

\title{
Introducción
}

El artículo 364 de la Ley 1819 de 2016 creó una contribución especial cuyo hecho generador es el pago de laudos arbitrales de contenido económico por valor superior a setenta y tres salarios mínimos legales mensuales vigentes, cifra que a su vez es la base gravable, y cuya tarifa es el máximo entre el $2 \%$ del monto del laudo y mil salarios mínimos legales mensuales vigentes. Este tributo, que no se extiende a sentencias proferidas por jueces o magistrados, es un nuevo y significativo obstáculo que se le impone a la justicia arbitral en Colombia, dificultando su progreso y desestimulando el uso de un método alternativo que ha demostrado ser eficiente para solucionar rápidamente, entre otras, controversias de alta complejidad.

Teniendo en cuenta las dificultades que plantea este nuevo gravamen para el arbitramento en Colombia, el presente artículo tiene dos objetivos. El primero es mostrar porque este tributo es tanto inconstitucional como inconveniente, esperando así que pronto ora la Corte Constitucional lo declare inexequible o el Congreso lo desmonte. Por su parte, el segundo objetivo recuerda que este nuevo gravamen no es el primero ni será el último ataque contra el arbitraje.

Para tal fin, la sección primera de este artículo describe esta nueva contribución parafiscal mientras que las secciones segunda y tercera explican, respectivamente, las razones por las cuales este tributo es inconstitucional e 
inconveniente. La cuarta sección argumenta que dicho gravamen es una nueva muestra de la aversión que ciertos sectores tienen hacia este tipo de medios alternativos de solución de controversias. Finalmente, la quinta sección concluye.

Este artículo cuenta con un método de investigación documental, lo que significa que la descripción del nuevo tributo, los argumentos por los cuales se considera que este es inconstitucional e inconveniente así como el marco teórico de la argumentación según la cual este gravamen es una muestra más de la repulsión de cierto sector se basan en un análisis de las normas, jurisprudencia y doctrina colombianas con breves referencias al derecho comparado.

\section{La nueva contribución especial para laudos arbitrales de contenido económico}

De conformidad con el artículo 364 de la Ley 1819 de 2016, los elementos de la nueva "Contribución especial para laudos arbitrales de contenido económico" son los siguientes: El sujeto activo es el Consejo Superior de la Judicatura, la Dirección Ejecutiva de la Administración Judicial, o quien haga sus veces, teniendo los dineros como destino el Fondo para la Modernización, Descongestión y Bienestar de la Administración de Justicia. ${ }^{1}$ El sujeto pasivo es "la persona natural o jurídica o el patrimonio autónomo a cuyo favor se ordene [mediante un laudo] el pago de valor superior a setenta y tres salarios mínimos legales mensuales vigentes"2, que para el año 2017 equivalen a \$53.853.341 (cifra

Artículo 364 de la Ley 1819 de 2016 del Congreso de la República (Colombia). No se debe confundir este gravamen con la contribución especial arbitral, creada por los artículos 17 a 22 de la Ley 1739 de 2014, que fueron modificados por el artículo 362 de la Ley 1819 de 2016. Este tributo también tiene como sujeto activo el Consejo Superior de le Judicatura, la Dirección Ejecutiva de Administración Judicial, o quien haga sus veces, con destino a la financiación del Sector Justicia y de la Rama Judicial, pero su sujeto pasivo no es la persona acreedora de una suma monetaria con motivo de un laudo arbitral sino los centros de arbitraje, los árbitros y los secretarios, mientras que el hecho generador no es el pago de una condena sino el pago de los gastos fijados en cada proceso, en el caso de los Centros de Arbitraje, y el proferir el laudo que pone fin al proceso con respecto a los árbitros y secretarios. Por su parte, la base gravable es el valor que corresponde a los centros de arbitraje, árbitros o secretarios, según sea el caso, mientras que la tarifa es del $2 \%$. Con todo, muchos de los argumentos de inconveniencia e inconstitucionalidad de la nueva contribución especial para laudos arbitrales de contenido económico son aplicables a la contribución especial arbitral. De hecho, la contribución a cargo de centros de arbitraje, árbitros y secretarios no existe en materia judicial (no existe un equivalente en impuestos sobre el salario de jueces y secretarios, por ejemplo) y es otra muestra de la inequidad con la que trata el legislador a estos dos tipos de justicia.

2 Véase $i d$. 
bastante baja). El hecho generador es el pago por parte del perdedor de un proceso arbitral a favor de quien lo ganó de la condena contenida en la parte resolutiva del respectivo laudo. ${ }^{3}$ La base gravable es el valor de dicho pago mientras que la tarifa es el $2 \%$ de dicha cifra sin que el monto total del impuesto supere los mil salarios mínimos legales mensuales vigentes, que para el 2017 son $\$ 737.717 .000$ (cifra muy alta). La persona natural o jurídica que realice el pago de la condena económica deberá retener la totalidad del tributo (así no figure como agente retenedor en el Registro Único Tributario) para proceder a consignar tal suma dentro de los siguientes tres meses a favor del sujeto activo.

Este nuevo tributo, como su nombre bien lo indica, es una contribución parafiscal por cuanto: (i) es un pago obligatorio para quienes estén dentro de los supuestos de hecho de la norma que crea el tributo, (ii) es singular ya que, a diferencia del impuesto, afecta a un determinado grupo social y económico (quienes obtienen condenas monetarias favorables en un proceso arbitral) sin que, a diferencia de las tasas, haya una contraprestación directa para el sujeto pasivo, ${ }^{5}$ (iii) tiene una destinación específica puesto que los recaudos se invierten en beneficio del propio sector, a diferencia de lo que sucede con los impuestos y las tasas, que salvo excepciones hacen parte de los ingresos corrientes de la Nación.

\section{La inconstitucionalidad de la contribución especial para laudos arbitrales de contenido económico}

A continuación se presentan algunas razones por las cuales la contribución especial para laudos arbitrales de contenido económico es contraria a la Constitución Política. Antes de ello, se formulan dos comentarios. Primero, estos argumentos, a pesar de su fuerza jurídica, no garantizan que la Corte Constitucional declare inexequible este tributo. Ya en el pasado la Corte ha sido demasiado respetuosa de la libertad del legislador en temas económicos y, en particular, en materia tributaria ${ }^{6}$. Segundo, la Corte Constitucional puede tener

3 Véase $i d$.

4 Véase $i d$.

5 Véase Sentencias C-713 de 2008 (Magistrada ponente: Clara Inés Vargas Hernández), C-368 de 2011 (Gabriel Eduardo Mendoza Martelo), y C-169 de 2014 (Magistrada ponente: María Victoria Calle Correa) de la Corte Constitucional. Véase también el artículo 28 del Estatuto Orgánico del Presupuesto (Decreto Ley 111 de 1996 de la Presidencia de la República).

6 Véase, e.g., Sentencia C-657 del 2015 de la Corte Constitucional (Magistrado Ponente: Jorge Iván Palacio Palacio). En este proceso se demandó el numeral 12 del artículo 38 de la Ley 1607 de 2012, que modificó el artículo 424 del Estatuto Tributario. Esta 
un sesgo a favor de la contribución toda vez que sus recursos se destinan a favor de la rama que hace parte?

\subsection{Violación de los principios de igualdad y de equidad tributaria}

El artículo 13 de la Constitución Política consagra el derecho a la igualdad y, en particular, el artículo 363 de la misma Carta extiende este derecho de igualdad al campo tributario al determinar, en su primer aparte, que "[e]l sistema tributario se funda en los principios de equidad, eficiencia y progresividad." De acuerdo con la jurisprudencia de la Corte Constitucional, ${ }^{8}$ la equidad tributaria o equidad horizontal implica "que sujetos con capacidad económica igual, o bajo una misma situación fáctica, contribuyan de igual manera".

La nueva contribución especial para laudos arbitrales viola tanto el derecho a la igualdad como el principio de equidad tributaria al otorgar un tratamiento fiscal diferente a dos sistemas de resolución de conflictos, favoreciendo el ordinario que es libre de impuestos y castigando con tributos al alternativo, que en este caso es el arbitraje. En otras palabras, sujetos bajo una misma situación fáctica, como por ejemplo dos sociedades involucradas en sendos litigios, una de las cuales recibe una condena económica a su favor en un proceso ante los jueces mientras la otra recibe una condena por el mismo monto en un proceso arbitral, contribuyen de manera desigual con las cargas tributarias, sin que haya una justificación constitucional para ello. Por el contrario, esta inequidad también viola el numeral noveno del artículo 95 de la Carta Política según el cual las personas contribuyen al financiamiento del Estado "dentro de conceptos de justicia y equidad".

norma determinó que el asfalto es un bien excluido de IVA mientras que el concreto está gravado con este impuesto. Tal diferencia le da una ventaja competitiva irrazonable al asfalto sobre el concreto, pudiendo ser escogido el primero por sus ventajas fiscales y no por sus características técnicas para algunas obras viales. A pesar del tratamiento inequitativo de la ley tributaria a dos productos que pueden ser sustitutos y mediante un análisis que desafortunadamente podría replicarse en el caso de la contribución arbitral que se analiza vis a vis la inexistencia de tal tributo en condenas judiciales, la Corte Constitucional equivocadamente consideró que la exclusión de IVA en el asfalto, que no se extiende al concreto, estaba justificada constitucionalmente con base en la autonomía legislativa que sobre tales temas tiene el Congreso de la República.

$7 \quad$ Véase artículo 363 de la Ley 1819 de 2016.

8 Véase, e.g., Sentencia C-169 de 2014 (MP. María Victoria Calle Correa) de la Corte Constitucional.

$9 \quad$ Ibid. 
En un mundo jurídico ideal, las personas que deseen resolver una controversia deberían escoger el foro al que acudirán, sea la justicia ordinaria o el arbitraje, entre otros métodos de resolución de conflictos, con base en las ventajas y desventajas procesales de cada uno de ellos, incluyendo el hecho de que el arbitraje genera gastos de funcionamiento y honorarios para los árbitros, pero no por razones fiscales. En contravía de esa neutralidad tributaria que deberían tener los sistemas procesales, el artículo 364 de la Ley 1819 de 2016 genera un incentivo para que las personas naturales o jurídicas escojan como foro la jurisdicción ordinaria y no la arbitral simple y llanamente porque la primera, pero no la segunda es libre de impuestos. En este orden de ideas, sin perjuicio de otro tipo de argumentos de inconstitucionalidad, y en relación con el principio de equidad tributaria, una contribución especial como la analizada podría ser constitucional pero sí y solo sí hay un gravamen equivalente para sentencias de contenido económico proferidas en la justicia ordinaria.

Alguna persona, no obstante, podría afirmar que la contribución especial sobre laudos de contenido económico no viola el principio de equidad tributaria porque el gravamen se puede evitar solucionando las controversias mediante la justicia ordinaria. Esto es una falacia por tres razones: (i) el solo hecho de que se limite la elección o de que se haga menos competitiva una opción ya de por sí es inconstitucional; (ii) muchos contratos de larga duración, que pueden generar o no litigios en el futuro, ya podrían haber estipulado una cláusula compromisoria a la fecha de creación del nuevo gravamen, requiriendo la rescisión de tal pacto el consentimiento de ambas partes, lo que muchas veces no es viable; y (iii) para muchas controversias, especialmente aquellas de alta complejidad legal, económica o técnica, el juez ordinario no es la mejor opción, ya que no tiene los conocimientos especializados con los que sí cuenta un árbitro elegido directamente por las partes.

La jurisprudencia constitucional sobre los aranceles judiciales que han existido en Colombia respalda el argumento de que la nueva contribución sobre laudos arbitrales viola el principio de equidad tributaria ${ }^{10}$. La Ley 1653 de 2013

10 Tres normas sobre aranceles judiciales han existido en Colombia. La primera fue la Ley 1285 de 2009, que reformó la Ley 270 de 1996 (Estatutaria de la Administración de Justicia), y que en su artículo 6 afirmó que la administración de justicia es gratuita "sin perjuicio de las agencias en derecho, costas, expensas y aranceles judiciales que se fijen de conformidad con la ley." La segunda norma fue la Ley 1394 de 2010, cuyo artículo 1 creó un arancel judicial, como contribución parafiscal, "destinado a sufragar gastos de funcionamiento e inversión de la administración de justicia." Como la Ley 1394 de 2010 fue derogada por el artículo 14 de la Ley 1653 de 2013 que, a su vez, fue declarada integralmente inexequible por la sentencia C-619 de 2014, se discute si la Ley 1394 de 2010 ha recobrado vigencia. La tercera norma sobre arancel judicial es la Ley 1653 de 2013, declarada inexequible. 
creó una contribución parafiscal destinada a financiar gastos de inversión de la Administración de Justicia (artículo 2) a cargo de los demandantes originales o de reconvención, además de otros sujetos procesales (artículo 6), cuyo hecho generador era la formulación de pretensiones dinerarias en algunos procesos judiciales (artículos 4 y 5), siendo la base gravable "las pretensiones dinerarias de la demanda o de cualquier otro trámite que incorpore pretensiones dinerarias" (artículo 7) mientras que la tarifa era del $1.5 \%$ de la base gravable sin que pudiera superar, en ningún caso, los doscientos salarios mínimos legales mensuales vigentes (artículo 8).

Mediante Sentencia C-169 de 2014, que no tuvo aclaraciones ni salvamentos de voto, la Corte Constitucional declaró inexequible en su integridad la Ley 1653 de 2013, desapareciendo de nuestro ordenamiento jurídico, por lo tanto, el arancel judicial. En esta sentencia, la Corte recordó que el principio de equidad tributaria es sacrificado intensamente cuando "dos sujetos o grupos de sujetos en iguales condiciones resultan gravados de manera desigual, sin justificación suficiente"11.

En particular, la Corte Constitucional consideró que el arancel judicial demandado violaba el principio de equidad por tres razones, las cuales son claramente aplicables a la contribución especial para laudos arbitrales que se analiza en el presente artículo. ${ }^{12}$ Primero, el valor del arancel judicial, al tener como base gravable las pretensiones de un proceso y no variables como la renta, la riqueza, la propiedad o el consumo, no tenía relación alguna ni consultaba la capacidad de pago del contribuyente, pudiendo incluso ser el monto del tributo variable superior a ésta ${ }^{13}$.

Segundo, el arancel judicial podía ser confiscatorio, lo que se deriva nuevamente del hecho de no consultar la capacidad contributiva del sujeto pasivo. ${ }^{14} \mathrm{Ni}$ siquiera el límite que existía en el arancel judicial, de doscientos salarios mínimos mensuales legales vigentes (que en el caso de la contribución especial de laudos arbitrales es de mil salarios mínimos) evita casos en los cuales una persona tuviese que destinar la totalidad de sus ganancias al pago del gravamen ${ }^{15}$. Con todo, alguien podría afirmar que la nueva contribución

\footnotetext{
11 Véase Sentencia C-169 de 2014 de la Corte Constitucional (MP. María Victoria Calle Correa).

12 Véase $i d$.

13 Véase $i d$.

14 Véase artículo 8 de la Ley 1653 de 2013 y 364 de la Ley 1819 de 2016 del Congreso de la República (Colombia).

15 Véase Sentencia C-169 de 2014 de la Corte Constitucional (MP. María Victoria Calle Correa).
} 
a los pagos derivados de laudos no es confiscatoria porque quien triunfa en sede arbitral se queda con el $98 \%$ de la condena monetaria. Este argumento olvida que toda o la mayor parte de la condena puede corresponder a daño emergente o a costas procesales que, en esencia, son reembolsos de pérdidas que se habían sufrido con anterioridad y que dieron lugar al respetivo litigio.

Tercero, la Corte Constitucional consideró que el arancel judicial podía "convertirse en una exacción desigual para sujetos con la misma capacidad de pago." ${ }^{16}$ En particular, la Corte consideró inconstitucional que la norma demandada no impidiera que dos sujetos con la misma capacidad de pago (igual renta, patrimonio, propiedades y consumo) pagasen cantidades desiguales, como sucedería si, en procesos con cuantías iguales, uno de ellos es beneficiario de una exención de la ley (por ejemplo, el demandante era una persona jurídica de derecho público), pero el otro no. ${ }^{17}$ "Yasí, dos personas con idéntica renta, riqueza, propiedad y nivel de consumo, siendo ambas demandadas, en procesos de la misma naturaleza, y con las mismas pretensiones dinerarias, acabarían pagando montos desiguales que, como se dijo en el punto anterior, no necesariamente consultan su capacidad de pago"18. Situación que, por supuesto, también se presenta con la nueva contribución especial en el caso de dos personas que inician procesos iguales, el uno en sede arbitral y el otro en sede judicial y que obtengan idénticas condenas económicas a favor.

En síntesis, la nueva contribución arbitral es discriminatoria y violatoria del principio de equidad tributaria al aplicarse a laudos pero no a sentencias $\mathrm{y}$, adicionalmente, al introducir nueva y subrepticiamente, aunque de manera exclusiva para laudos arbitrales, el arancel judicial. La diferencia es que ya el pago no se hace al presentar la demanda o admitirse ésta (por la puerta delantera) sino al pagarse la condena proferida por un árbitro (por la puerta de atrás).

\subsection{Violación del principio de progresividad tributaria}

Además de ir en contravía de la equidad tributaria, la nueva contribución sobre laudos arbitrales también es regresiva, en los términos del artículo 363 de la Constitución Política ${ }^{19}$, por cuanto (i) no tiene tarifas diferenciales, siendo el porcentaje aplicable siempre igual cuando el monto a pagar supera los mil salarios

\footnotetext{
16 Id.

17 Véase artículo 5 de la Ley 1653 de 2013 del Congreso de la República (Colombia).

18 Sentencia C-169 de 2014 de la Corte Constitucional (MP. María Victoria Calle Correa).

19 La progresividad, según la Corte Constitucional, exige que "las personas con más capacidad económica contribuyan en mayor medida." Véase $i d$.
} 
mínimos legales mensuales vigentes, y (ii) este gravamen podría convertirse en una barrera de acceso a la justicia.

Nuevamente, las consideraciones hechas por la Corte Constitucional al declarar inexequible el arancel judicial de la Ley 1653 de 2013 son aplicables en materia de la contribución especial objeto de análisis, como se explica a continuación. ${ }^{20}$ En relación con el punto (i) del párrafo anterior, la Corte halló una regresividad manifiesta en este arancel judicial porque la norma demandada permitía que quienes solicitaran pretensiones elevadas de dinero nunca tuviesen que pagar un tributo superior a doscientos salarios mínimos mensuales legales vigentes ${ }^{21}$. Una situación similar sucede en materia de la contribución especial de laudos, con la única diferencia de que en este caso el límite es un poco más alto, de mil salarios mínimos.

En cuanto al punto (ii), la Corte sostuvo que el hecho de que el arancel judicial pudiese convertirse en una barrera económica procesal para quienes no tuviesen buena capacidad de pago era una situación constitucionalmente no aceptable teniendo en cuenta que el pago del tributo sería una condición de acceso a un servicio fundamental, como lo es la administración de justicia ${ }^{22}$. A primera vista, dos diferencias entre el arancel judicial y la contribución especial de laudos de contenido económico podrían hacer inaplicable el anterior razonamiento, aunque un análisis más profundo desvirtúa este razonamiento inicial.

En primer lugar, podría pensarse que no hay barreras de acceso por cuanto: (i) las partes pueden acudir a la justicia tradicional, caso en el cual no se genera ningún gravamen, y (ii) las partes que utilizan el arbitraje como método alternativo de solución de controversias, al ser este sistema oneroso, cuentan con los recursos para pagar el impuesto. El primer argumento ya se desvirtuó al hablar del principio de equidad tributaria, recordando que el derecho de acceso a la justicia no solo es a la tradicional sino también a los métodos alternativos. De lo contrario, de nada serviría que el artículo 116 de la Constitución Política permita que las partes de una controversia habiliten a particulares para administrar justicia. El segundo argumento, por su parte, es un mito. El

$20 \quad$ Véase $i d$.

$21 \quad$ Véase id. ("[P]ara la Ley es indiferente que mientras unas personas se vean obligadas a destinar la casi o absoluta totalidad de los frutos de su actividad económica, para pagar el arancel, otras -las que tienen mayor capacidad de pago- nunca se vean ante la necesidad de pagar más de doscientos salarios mínimos legales mensuales vigentes. La regulación no sólo no es entonces progresiva, sino que de hecho tiene implicaciones regresivas").

22 Véase $i d$. 
arbitraje es mucho menos costoso de lo que usualmente se piensa, ${ }^{23}$ razón por la cual muchas de las personas naturales o jurídicas que participan en él pueden decidir no acudir más a este método o sufrir expensas muy significativas con ocasión del nuevo tributo.

En segundo lugar, alguien podría afirmar que, a diferencia del arancel judicial, la nueva contribución especial no es una barrera de acceso a la justicia porque ésta se cobra al final del proceso (con el pago de la condena) y no como requisito de inicio. Esto no es necesariamente cierto ya que el nuevo tributo puede desincentivar a ciertas personas a presentar una demanda en sede arbitral con lo cual la barrera de acceso sí existe ${ }^{24}$. Piénsese, por ejemplo, en la siguiente situación. La empresa X planea demandar a la empresa Y por incumplimiento de contrato. Presentar la demanda en sede judicial no es una opción por el tiempo que tomará este proceso y porque el juez competente, en todas sus instancias, no tendrá los conocimientos sobre temas jurídicos y económicos de alta complejidad. La empresa $X$ estima que, en caso de presentar una demanda, la probabilidad de obtener un laudo favorable que otorgue el derecho a una suma de $\$ 100.000 .000$ es del $45 \%$, existiendo un $15 \%$ de que no se otorgue ninguna suma a favor, caso en el cual se pierden los gastos del proceso, estimados en $\$ 30.000 .000$, y un $40 \%$ de que, con motivo de una demanda de reconvención de la empresa $Y$, haya que pagarle a esta $\$ 100.000 .000$. El valor esperado de la condena a favor es de $\$ 100.000 .000$ * $45 \%$ - \$30.000.000*15\% - \$100.000.000*40\% = \$500.000. Aunque la situación es cercana al límite, en este caso se justifica presentar la demanda. Asuma ahora que, con motivo de la contribución especial sobre laudos de contenido económico, en el primer escenario hay que pagar un $2 \%$ de este nuevo tributo (que es inferior al tope de mil salarios mínimos mensuales legales vigentes). En tal caso, el valor esperado de la condena a favor es $\$ 98.000 .000 * 45 \%$ $\$ 30.000 .000 * 15 \%-\$ 100.000 .000 * 40 \%=-\$ 400.000$. Como el valor es negativo, la contribución hará que el potencial actor prefiera no presentar una demanda arbitral. Desde una perspectiva menos matemática y más jurídica, y utilizando las palabras de la Corte Constitucional: "[l]as medidas que puedan producir un efecto de desaliento sobre el uso de la justicia, y de las posiciones y recursos judiciales de defensa, deben someterse al más estricto escrutinio judicial por parte de la Corte Constitucional". ${ }^{25}$

23 Véase Artículo 32 del Decreto 1829 del 2013 del Ministerio de Justicia de Colombia, compilado en el Decreto Único Reglamentario 1069 de 2015.

24 Véase generalmente Posner, Richard, Economic Analysis of Law, Octava edición, Nueva York, Wolters Kluwer Law \& Business, 2014, pp. 553-674.

25 Sentencia C-169 de 2014 de la Corte Constitucional (MP. María Victoria Calle Correa). 


\subsection{Violación del derecho de acceso a la justicia}

Como consecuencia de la vulneración de los principios de equidad tributaria y de progresividad, la nueva contribución arbitral sobre laudos de contenido económico también viola el derecho de acceso a la justicia, consagrado en el artículo 229 de la Carta Política. Recurriendo nuevamente a las palabras de la Corte Constitucional, "[e]l desproporcionado sacrificio que introduce el arancel judicial, en los principios de justicia, equidad y progresividad tributarias, acarrea la violación de los derechos de acceso a la justicia y al debido proceso"26.

Adicionalmente, el derecho de acceso a la justicia también se ve seriamente afectado cuando una ley, mediante un nuevo tributo, le pone obstáculos a uno de los caminos a través del cual se puede acceder a la justicia, de tal manera que subsista solo un camino sin impedimentos monetarios, el cual acaba teniendo el monopolio de la administración de justicia, en contravía con el sentir de la Constitución Política.

Además de lo anterior, en línea con lo ya afirmado en los numerales anteriores, y como parte del derecho de acceso a la justicia, el nuevo gravamen puede hacer inoperante el artículo 116 de la Constitución Política, cuya última parte señala que "[l]os particulares pueden ser investidos transitoriamente de la función de administrar justicia en la condición de jurados en las causas criminales, conciliadores o en la de árbitros habilitados por las partes para proferir fallos en derecho o en equidad, en los términos que determine la ley." Pues bien, el nuevo tributo hace que, en muchos casos y por razones económicas, las partes de una controversia no tengan incentivos para habilitar a particulares a administrar justicia, haciendo inoperante esta norma constitucional.

\subsection{Violación del principio de reserva de ley}

Recuérdese que según el principio de reserva de ley, consagrado en el artículo 338 de la Constitución Política, "[e]n tiempo de paz, solamente el Congreso, las asambleas departamentales y los concejos distritales y municipales podrán imponer contribuciones fiscales o parafiscales". Tal poder tributario, no obstante, no es absoluto. Entre otros límites, el numeral 12 del artículo 150 de la Constitución indica que el Congreso de la República, mediante leyes, puede "[e] stablecer contribuciones fiscales $y$, excepcionalmente, contribuciones parafiscales en los casos y bajo las condiciones que establezca la ley." (Las subrayas son propias). Esta norma implica, según la Corte, un escrutinio constitucional más

$26 \quad I d$. 
intenso en el caso de las contribuciones parafiscales, como lo es el nuevo tributo, en comparación con los impuestos y las tasas. ${ }^{27}$ De no ser así, las contribuciones parafiscales podrían convertirse "en la forma ordinaria y regular de financiar los gastos e inversiones del Estado, que en principio es un deber de todas las personas y los ciudadanos, y no exclusivamente una obligación de un sector" ${ }^{28}$ según lo dispuesto por el numeral noveno del artículo 95 de la Carta Política.

Dicho intenso escrutinio implica recordar que muchos tributos tienen finen fiscales y extra fiscales. En cuanto a los primeros, la Corte Constitucional ha afirmado que las formas de financiación de la rama judicial deben ser razonables $^{29}$. En relación con los fines extra fiscales, estos generalmente son desestimular una actividad nociva, como sucede con los gravámenes al tabaco $^{30}$. Tal finalidad en el arancel judicial, a pesar de que existían medios menos restrictivos, tenía sentido: evitar demandas con cuantías temerarias que podrían desgastar innecesariamente la infraestructura judicial. ${ }^{31}$ En el caso de la contribución especial sobre laudos arbitrales, en contraste, el propósito de la norma sería el desincentivar el uso de la justicia arbitral, lo que no parece una justificación razonable desde el punto de vista constitucional. Como bien lo dice la Corte Constitucional, "[n]o es lo mismo consumir tabaco que acceder a la administración de justicia, o que ejercer una posición de defensa dentro de un proceso judicial. La imposición de gravámenes sobre el consumo del cigarrillo, si bien tiene por supuesto límites, no se ha de someter a un escrutinio tan estricto como al que ha de sujetarse una detracción sobre el uso de la administración de justicia"32.

\section{La inconveniencia de la contribución especial para laudos arbitrales de contenido económico}

Además de que el nuevo tributo discutido en este artículo es inconstitucional, con base en los argumentos ya indicados, tal gravamen también es inconveniente, por las razones que se indican a continuación.

\footnotetext{
27 Véase $i d$.

28 Véase $i d$.

29 Sentencia C-169 de 2014 de la Corte Constitucional (MP. María Victoria Calle Correa).

30 Véase $i d$.

31 Véase $i d$.

32 Véase id. Además, si se quisiera desestimular el uso de la justicia arbitral, la forma de hacerlo no es gravando ésta en forma exclusiva sino haciendo más eficiente a su competencia, la justicia tradicional.
} 


\subsection{Todo impuesto genera distorsiones en la actividad gravada}

Desde mucho tiempo atrás, la literatura microeconómica ha identificado los efectos nocivos de los impuestos sobre las actividades gravadas, que en este caso es el arbitraje ${ }^{33}$. Estas consecuencias son principalmente los siguientes dos: (i) la reducción de la cantidad ofrecida en un determinado mercado (e.g., el número de arbitrajes); y (ii) el incremento de su precio, pudiendo trasladarse este mayor costo a las personas que compran bienes y servicios de los usuarios de estos métodos alternativos de solución de controversias ${ }^{34}$. Este punto (ii), así sea obvio, implica que las partes no solo han de sufragar los gastos administrativos del respectivo centro de arbitraje así como los honorarios de los árbitros y del secretario sino también, en caso de resultar acreedores de una pretensión económica, el $2 \%$ de su valor con el tope ya mencionado de mil salarios mínimos legales mensuales vigentes ${ }^{35}$.

Aunque todo tributo genera efectos distorsivos en los mercados en los cuales opera, es claro que el Estado necesita ingresos para subsistir y, por ello, algunos tributos son un mal necesario. Como lo dice una cita aparentemente apócrifa de Winston Churchil, there is no such thing as a good tax ${ }^{36}$. Con todo, los tributos creados deben ser aquellos que tengan los mínimos efectos nocivos y que generen el mayor recaudo posible, además de que no deben discriminar entre actividades similares, características que no parece tener la contribución especial analizada en el presente artículo. En el caso particular del recaudo, igualmente, este no solo recaerá sobre muy pocas empresas, en contravía con el objetivo de ampliar la base tributaria, sino que tampoco será de tan gran cuantía para el Estado. En efecto, el número de arbitrajes en Colombia al año puede ser cercano a cuatrocientos. ${ }^{37}$ Asumiendo que cada arbitraje genere una condena económica igual a $\$ 500.000 .000$, el valor total recaudado por año será de $\$ 4.000 .000 .000$, una cifra insignificante en relación con el presupuesto colombiano.

33 Véase, e.g., Samuelson, Paul y Nordhaus, William, Economics, Edición 19, Nueva York, McGraw-Hill Education, 2009, pp. 87-101; y Mankiw, N. Gregory, Principles of Economics, Edición 7, Nueva York, South-Western College Publishers, 2014, pp. 155-71.

34 Véase $i d$.

35 Véase Artículo 32 del Decreto 1829 del 2013 del Ministerio de Justicia de Colombia, compilado en el Decreto Único Reglamentario 1069 de 2015.

36 Ningún impuesto es bueno (traducción libre del autor de este texto). Sobre la posibilidad de que Winston Churchill nunca haya dicho tal frase, véase https://richardlangworth. com/taxes (última visita, marzo 10, 2017).

37 Véase Portafolio, Bogotá, 19 de agosto de 2015, "El arbitraje colombiano es de talla mundial", Entrevista a Rafael Guillermo Bernal, disponible en: http://www.portafolio.co/ economia/finanzas/arbitraje-colombia-talla-mundial-37224 
De otro lado, algunos impuestos, a pesar de no generar grandes recaudos, tienen fines extra fiscales positivos al generar externalidades positivas (por ejemplo, estímulos a la inversión, como sucede con el artículo 115-2 del Estatuto Tributario que permite deducir el IVA pagado en la adquisición o importación de bienes de capital) o reducir externalidades negativas, como es el caso del nuevo impuesto al carbono, consagrado en los artículos 221 y siguientes de la Ley 1819 de 2016, que busca reducir la contribución de Colombia al calentamiento global, o del impuesto al consumo de cigarrillo y tabaco, regulado en las leyes 223 de 1995 y 1393 de 2010, que buscan reducir el impacto en la salud pública de enfermedades pulmonares.

La nueva contribución arbitral, en contraste y como ya se dijo en la sección segunda, no desestimula externalidades negativas y, por el contrario, desincentiva la externalidad positiva que el arbitraje genera sobre la justicia tradicional al descongestionarla y vía, competencia, estimularla a ser más eficiente. En otras palabras, es un contrasentido crear un tributo para descongestionar la misma actividad que se grava. Y en efecto, eso es lo que sucede. Así parezca sorprendente o paradójico, la norma está desincentivando un sistema de solución de controversias alternativo que, entre múltiples beneficios, tiene la ventaja de aligerar la carga de la rama judicial para, acto seguido, destinar los recursos recaudados a descongestionar esta última. Esto tiene la misma lógica que extraer sangre de un enfermo con destino a otro enfermo. En resumen, la solución a los problemas de la rama judicial en Colombia no pasa por acabar o perseguir lo que bien funciona, así no sea perfecto (el arbitraje), sino en solucionar las fallas estructurales de la administración de justicia.

\subsection{La nueva contribución arbitral genera incentivos perversos}

Además de los efectos microeconómicos nocivos ya mencionados, la contribución arbitral genera los siguientes incentivos perversos para las partes que desean solucionar una controversia. En primer lugar, estas pueden desistir de pactar una cláusula compromisoria o un compromiso y, en su lugar, acudir a la justicia ordinaria. Esto, no obstante, no será lo más recomendable si la controversia se relaciona con problemas fácticos, jurídicos, económicos o técnicos de alta complejidad para los cuales puede ser mejor nombrar como árbitros a expertos (que incluso pueden ser no abogados) antes que dejar el asunto en manos de jueces, que son competentes para temas generales, pero no para asuntos de gran especialidad. Como segunda desventaja, el ahorro en el posible tributo no compensará las mayores demoras de la justicia ordinaria. Recuérdese que, según el artículo 10 de la Ley 1563 de 2012, mientras un proceso arbitral suele durar no más de seis meses prorrogables por otros seis (a menos que las partes señalen 
otro término $)^{38}$ y que el proceso es de única instancia ${ }^{39}$, el proceso judicial en primera instancia dura como mínimo un año ${ }^{40}$, más el tiempo correspondiente a las instancias posteriores, que pueden ser dos más en jurisdicción ordinaria más otras tres en sede de tutela. Téngase en cuenta, además, que según el informe Doing Business del Banco Mundial, hacer cumplir un contrato en Colombia en vía judicial, y solo teniendo en cuenta la primera instancia, toma 1.288 días y cuesta el $45.8 \%$ del valor reclamado ${ }^{41}$.

Alternativamente, las partes podrían, para evitar el pago del tributo, iniciar el proceso arbitral pero, poco antes de que se profiera el laudo, conciliar o transigir sus diferencias, evitando así el pago del tributo. Una segunda posibilidad, y de conformidad con los artículos 59 a 61 de la Ley 1563 de 2012, consistiría en no solucionar el conflicto por medio de un arbitraje sino de un amigable componedor, caso en el cual no operaría el gravamen. Nuevamente, las partes estarían escogiendo el método para solucionar su controversia no por razones procesales, como debería ser, sino por su impacto tributario.

De otro lado, téngase en cuenta que la literatura es clara al afirmar que todos los remedios (es decir, la indemnización por daños y perjuicios) son infra compensatorios. ${ }^{42}$ Ningún demandante recupera la totalidad de los daños que ha sufrido con ocasión, para referirnos solo al campo contractual, de un incumplimiento de la otra parte ${ }^{43}$. Es el caso, para dar algunos ejemplos, del tiempo que los empleados de una empresa invierten en el litigio, que tiene un valor monetario que no se reembolsa, además del costo de oportunidad de no dedicar ese tiempo a otras labores, de parte de los honorarios de los abogados que las agencias en derecho no siempre reconocen por tener límites bajos ${ }^{44}$, y de ciertos perjuicios que se sufren pero que no se reconocen en sede arbitral por no poderse probar, tales como los daños de reputación o lucros cesantes

$38 \quad$ Véase artículo 10 de la Ley 1563 de 2012.

39 Aunque los recursos de anulación, revisión y tutela pueden alargar este término.

40 Véase artículo 121 de la Ley 1564 de 2012 (Código General del Proceso).

41 Véase Banco Mundial, Doing Business (Enforcing Contracts), Colombia, disponible en: http://www.doingbusiness.org/data/exploreeconomies/colombia\#enforcing-contracts

42 Véase, generalmente, Gaviria, Juan Antonio, El Problema del Hold-up en el Derecho de Contratos (Colombia, México y Estados Unidos), Editorial Porrúa, Ciudad de México, 2015, pp. 215-230.

43 Véase $i d$.

44 Véase el Acuerdo No. PSAA16-10554 - Liquidación de Agencias en derecho del Consejo Superior de la Judicatura. 
de cierta incertidumbre ${ }^{45}$. Las normas, por lo tanto, deberían reducir esta infra compensación de los remedios y no, como lo hace la nueva contribución especial para laudos arbitrales, incrementar ésta.

\subsection{La nueva contribución incrementa los costos de transacción de los contratos}

La literatura sobre análisis económico del derecho ha explicado no sólo porque no existen los contratos completos (aquellos que asignan a las partes los riesgos de todas, absolutamente todas, las circunstancias que puedan acaecer en el futuro) sino además porque este tipo de contratos es ineficiente ${ }^{46}$. En efecto, estipular un contrato con un altísimo grado de precisión haría que los costos de negociar y redactar las cláusulas (los costos de transacción) fueran supremamente elevados ${ }^{47}$. Así las cosas, existe un nivel eficiente del detalle de las cláusulas de los contratos, aquel a partir del cual el costo de seguir negociando (que incluye el costo de oportunidad de demorar el inicio de la ejecución y, por lo tanto, de dilatar el provecho esperado del contrato) es mayor al beneficio de tener un mayor grado de detalle y, por lo tanto, de minimizar litigios futuros por cláusulas ambiguas ${ }^{48}$. En términos matemáticos, el nivel de detalle es eficiente a partir del momento en el que, donde CT son los costos de seguir negociando el contrato, CL son los costos no recuperables de un futuro litigio en el que se solicite a un juez o a un árbitro superar una ambigüedad contractual y PL, como el litigio puede o no suceder, es la probabilidad de que este ocurra ${ }^{49}$.

En este orden de ideas, cierto nivel de ambigüedad en las cláusulas de los contratos no solo es inevitable sino deseable ${ }^{50}$. Para mencionar dos ejemplos, y en el contexto de un contrato de obra, una de cuyas partes es el dueño del terreno y la otra el contratista, es preferible simplemente estipular (i) que el dueño debe entregar el terreno en óptimas condiciones que detallar, en varias páginas, que se entiende por tal concepto, o (ii) acordar que el constructor debe ser un experto

45 Véase, generalmente, Gaviria, Juan Antonio, El Problema del Hold-up en el Derecho de Contratos (Colombia, México y Estados Unidos), Editorial Porrúa, Ciudad de México, 2015, pp. 215-230.

46 Véase $i d$.

47 Véase $i d$.

48 Véase $i d$.

49 Véase $i d$.

50 Véase $i d$. 
en el trabajo a realizar, sin precisar el grado de estudios y experiencia que deben tener sus empleados ${ }^{51}$.

Pues bien, la nueva contribución especial sobre laudos arbitrales tiene el efecto nocivo de incrementar los costos de transacción de la negociación de los contratos debido al incremento de la variable CL. En ausencia de este gravamen, un litigio arbitral es menos costoso y, por lo tanto, las partes pueden preferir esa erogación al gasto asociado con prolongar las negociaciones. En contraste, con el gravamen del $2 \%$, las partes tendrán un incentivo para minimizar la ocurrencia de un litigio futuro mediante un mayor detalle o una menor ambigüedad de las cláusulas de su contrato, lo que alargará las negociaciones e incrementará el costo de éstas.

\subsection{La nueva contribución genera inconvenientes de tipo procesal}

Aunque la norma no lo dice expresamente, y teniendo en cuenta que las normas no suelen tener efectos fuera del territorio colombiano, el nuevo gravamen opera solo para laudos cuya sede haya estado en parte del territorio colombiano. Como el gravamen no aplica para laudos proferidos en arbitrajes internacionales que tengan sede en otro país ${ }^{52}$, la norma hace inútil buena parte del esfuerzo de la Ley 1563 de 2012 para convertir a Colombia en un lugar atractivo como sede de tribunales internacionales ${ }^{53}$. En efecto, las partes de un contrato internacional $\mathrm{y}$, asimismo, de un litigio internacional, preferirán elegir como sede ciudades no colombianas y así ahorrarse el $2 \%$ de las sumas futuras que el tribunal decrete a favor de una de ellas.

Un segundo problema se relaciona con un laudo que no ha sido anulado por la jurisdicción competente pero que ha sido modificado por una tutela. En este caso, pareciera que la suma de dinero que la sentencia de tutela ordene pagar no estaría sujeta al tributo. Eso está muy bien, pero lo propio debería ocurrir con el laudo.

51 Estos son ejemplos que menciona el Profesor Alfredo Bullard en una conferencia disponible en el siguiente enlace: https://www.youtube.com/results?search_query=analisis+economico+del+derecho+alfredo+bullard+ (última visita, marzo 10 de 2017).

52 Con todo, téngase en cuenta que no es el arbitraje en sí el que debe calificarse como internacional, toda vez que el arbitraje no admite adjetivos, sino el contrato que le da origen. Véase Silva Romero, Eduardo, De la calificación del arbitraje de internacional en el Estatuto de Arbitraje Nacional e Internacional colombiano, en Estatuto Arbitral Colombiano, Bogotá D.C., Legis, 2013, pp. 345-62.

53 Véase Gaviria, Juan Antonio, Comentarios sobre las nuevas normas colombianas en materia de arbitraje internacional, Revista de Derecho Privado, Universidad Externado de Colombia, pp. 259-81, Número 24 (2013). 
Un tercer y último problema se relaciona con laudos en los cuales ambas partes reciban condenas monetarias a favor. En tal caso, cada parte debería pagar el $2 \%$ de lo otorgado a pesar de que, vía compensación y en virtud del artículo 1714 del Código Civil, solo una de ellas recibirá el neto. Ello, sobra decirlo, es injusto.

\subsection{La nueva contribución es anti técnica desde el punto de vista tributario}

El artículo 364 de la Ley 1819 de 2016 se limita a establecer una contribución parafiscal del $2 \%$ sobre el valor de la condena en laudos arbitrales de contenido económico cuando éste es superior a setenta y tres salarios mínimos legales mensuales vigentes. Al no distinguir, se asume que el gravamen cubre todos los conceptos que puedan hacer parte de la parte resolutiva del laudo ${ }^{54}$, lo cual es injusto por las razones que a continuación se indican, las cuales hacen alusión a las controversias contractuales, que son las más comunes en tribunales de arbitramento ${ }^{55}$.

En primer lugar, una de las partes puede solicitar exitosamente la nulidad de un acto jurídico y, como consecuencia, tener el derecho a reversar una transacción (por ejemplo, de compraventa). ¿Es esta una condena de contenido económico? Podría pensarse que no porque no hay una orden de pagar una suma de dinero y, en tal caso, no se presentaría el hecho generador del tributo. Pero si se afirma lo contrario ${ }^{56}$, por cuanto lo ordenado puede implicar la devolución de un precio pagado, el gravamen sería injusto porque estaría castigando a una parte que exitosamente pretende que se le regrese a la situación en la que estaba antes de celebrar el contrato respectivo.

Segundo, un laudo puede conceder una pretensión de indemnización por daño emergente ("el perjuicio o la pérdida que proviene de no haberse cumplido la obligación o de haberse cumplido imperfectamente, o de haberse retardado su cumplimiento" $)^{57}$. En tal caso, la parte que obtiene la condena a su favor está simplemente recuperando lo que perdió con ocasión de los hechos que dieron lugar al litigio, siendo entonces injusto que el Estado le descuente un $2 \%$ de tal monto.

$54 \quad$ Véase artículo 26 del Código Civil.

$55 \quad$ Véase supra nota 38.

56 Según el Diccionario de la Real Academia de la Lengua Española, una condena es toda pena que no se limite a absolver la demanda. Véase www.rae.es. Condena económica sería aquella que implica la obligación de dar una suma de dinero o de hacer o no hacer algo que tiene un costo o que es valorable en dinero.

57 Artículo 1614 del Código Civil.

34 Revista del Instituto Colombiano de Derecho Procesal • No. 46 
Tercero, un laudo puede conceder una pretensión de lucro cesante ("la ganancia o provecho que deja de reportarse a consecuencia de no haberse cumplido la obligación, o cumplido imperfectamente, o retardado su cumplimiento" $)^{58}$. Como esta suma reemplaza a la ganancia que se hubiera obtenido de haberse cumplido el contrato, ella será un ingreso gravable para efectos del impuesto de renta, a tarifas entre el 0 y el $35 \%$ para personas naturales ${ }^{59}$, y del $33 \%$ (34\% para el 2017) más una posible sobretasa del 6\% en el 2017 y del $4 \%$ en el 2018 para personas jurídicas ${ }^{60}$. Ya de por sí es bastante alta la tarifa del impuesto sobre la renta como para que un nuevo gravamen incremente la carga tributaria en un $2 \%$. Además, es injusto que un mismo laudo de contenido económico de lugar a dos tributos (además de que si el pago se hace a través de canales financieros se causa el gravamen a los movimientos financieros) ${ }^{61}$, así el uno sea un impuesto que se genere por causación o devengo (en el caso de las personas jurídicas ${ }^{62}$ y el otro sea una contribución parafiscal que se origine con el pago o movimiento de efectivo ${ }^{63}$.

Cuarto, un laudo puede conceder el pago de una cláusula penal pactada en un contrato, la cual puede ser estimativa de perjuicios o, alternativamente, ser adicional a éstos. ${ }^{64}$ En uno u otro caso el análisis es el mismo del párrafo anterior toda vez que, para efectos del impuesto sobre la renta, el valor de la cláusula penal será un ingreso gravable ${ }^{65}$.

Quinto, un laudo puede indexar las anteriores condenas para compensar la pérdida de poder adquisitivo con motivo de la inflación. En estos casos, como lo buscado es simplemente mantener el valor en el tiempo de las sumas asignadas, es injusto que este concepto este gravado con la nueva contribución especial para laudos arbitrales.

Sexto, un laudo usualmente asigna las costas y las agencias en derecho a ambas o a una de las partes. La parte a favor de quien se consagran estos pagos

\footnotetext{
58 Artículo 1614 del Código Civil.

59 Véase artículo 241 del Estatuto Tributario. Muy posiblemente el ingreso que reciba la persona natural se clasificará como una renta no laboral. Si, además, la condena del laudo es superior a 4.000 UVT (\$127.436.000 para el 2017), la tasa aplicable será la máxima, del 35\%.

60 Véase artículo 240 del Estatuto Tributario.

61 Véase artículo 871 del Estatuto Tributario.

62 Véase artículo 28 del Estatuto Tributario. Para las personas naturales, véase el artículo 27 del mismo estatuto.

63 Véase artículo 364 de la Ley 1819 de 2016.

64 Véase artículo 1599 del Código Civil.

65 Véase artículo 9 del Estatuto Tributario.
} 
simplemente recupera parte de los gastos que había hecho por lo que, nuevamente, es injusto afectar estos con la contribución parafiscal que aquí se discute.

De otro lado, y para terminar esta sección, téngase en cuenta que el régimen de deducciones en el impuesto sobre la renta es suficientemente estricto con la parte que pierde un proceso arbitral o judicial como para agravar la situación cuando se logra el resultado contrario luego de un gran esfuerzo (triunfar en el proceso). En efecto, y según el literal c) del numeral segundo del artículo 105 del Estatuto Tributario, no son deducibles del impuesto sobre la renta las "multas, sanciones, penalidades, intereses moratorios de carácter sancionatorio y las condenas provenientes de procesos administrativos, judiciales o arbitrales diferentes a las laborales con sujeción a lo prevista en el numeral 3 del artículo 107-1 de este estatuto"66.

Aunque no es el objeto del presente texto, esta norma es poco técnica al negar la deducción de gastos que, si se hubieran hecho voluntariamente, si serían aceptados como costos o expensas fiscales ${ }^{67}$. Tal es el caso de una parte que consideró que existían razones de derecho para no pagar voluntariamente el precio de un bien adquirido, el flete de un transporte contratado, el canon de arrendamiento de un local comercial, los intereses de un contrato de mutuo en el cual es el deudor, la mal llamada "cesantía comercial" en el caso de un contrato de agencia mercantil ${ }^{68}$, entre otras situaciones, y que tuvo que pagar tales valores porque un juez o un tribunal de arbitramento consideró que había razones de hecho y de derecho para ello.

\section{La nueva contribución especial como una muestra más de la aversión de ciertos sectores hacia el arbitraje}

Una vez mostradas las razones por las cuales la contribución especial sobre laudos arbitrales de contenido económico es inconstitucional e inconveniente, la presente sección muestra como este nuevo gravamen no es un accidente sino que es el reflejo de una animadversión de cierta parte del Congreso y de la rama judicial hacia el arbitraje, que podría ver este medio alternativo como una competencia indeseada, al sustraer casos de cierta relevancia, en vez de verlo como un aliado que les motiva a ser más competitivos y que les reduce su carga

66 El numeral segundo del artículo 107-1 establece que son aceptados como deducciones siempre y cuando se encuentren debidamente soportadas y hagan parte del giro ordinario del negocio "[l]os pagos salariales y prestacionales, cuando provengan de litigios laborales ... siempre y cuando se acredite el cumplimiento de la totalidad de los requisitos para la deducción de salarios."

67 Véase, e.g., artículo 107 del Estatuto Tributario.

68 Véase artículo 1324 del Código de Comercio. 
laboral. La animadversión no viene de la rama ejecutiva teniendo en cuenta que la nueva contribución especial sobre laudos arbitrales no estaba en el proyecto de reforma tributaria presentado originalmente por el gobierno al Congreso de la República. Tal situación, además, permite anticipar que, posiblemente, este no sea ni el primer ni último ataque, ya sea de índole tributaria o no, contra el arbitraje en Colombia. De hecho, es por estos ataques que Colombia lamentablemente no ha sido tan abierta y amigable al arbitraje como otros países, tales como Estados Unidos ${ }^{69}$ y Francia $^{70}$.

En lo que atañe al sector legislativo, esta no es la primera vez que se promulgan normas que dilatan leyes que sí fortalecen este método alternativo de solución de controversias o que se promulgan normas que debilitan el arbitraje. En cuanto al primer caso, y si bien el actual Estatuto Arbitral (Ley 1563 de 2012) es una ley pro arbitraje ${ }^{71}$ no se debe olvidar que esta norma solo se promulgó luego de muchos años de discusión y de innumerables críticas contra ella ${ }^{72}$.

En relación con lo segundo, recuérdese que la versión original del numeral 12 del artículo 43 de la Ley 1480 de 2011 (Estatuto del Consumidor) consideraba abusiva y, por lo tanto ineficaz de pleno derecho, toda estipulación que obligara al consumidor a acudir a la justicia arbitral. Afortunadamente, dicha norma de extremo fue derogada por el artículo 118 de la Ley 1563 de 2012 (Estatuto Arbitral) - aunque otra podría haber sido la situación si el Estatuto arbitral se hubiera promulgado un poco antes y el Estatuto del consumidor un poco después con lo cual esta restricción continuaría vigente. Así, hoy en día una cláusula arbitral en un contrato de consumo solo es abusiva si "genera un "desequilibrio injustificado en perjuicio del consumidor"73 o si afecta "el tiempo, modo o lugar en que el consumidor puede ejercer sus derechos." ${ }^{74}$ Decimos afortunadamente porque la norma original del Estatuto del Consumidor privaba al consumidor de acceder a un foro que en ocasiones, y sí él así lo acepta, puede ser beneficioso, tal como sucede en otros países ${ }^{75}$. En todo caso, si la cláusula es verdaderamente abusiva, subsiste el control judicial ${ }^{76}$.

\footnotetext{
69 Véase, e.g., the Federal Arbitration Act (Estados Unidos).

70 Véase generalmente Gaillard, Emmanuel y Savage, John, Nueva York, Kluwer Law International, 1999.

71 Véase Gaviria, supra nota 54, p. 259.

72 Véase $i d$.

73 Primer inciso del artículo 42 de la Ley 1480 de 2011.

$74 \quad$ Id.

75 Véase, e.g., Federal Arbitration Act (Estados Unidos).

76 Véase, e.g., Brower v. Gateway 2000, Inc. 676 N.Y.S.2d 569 (N.Y. App. Div. 1998) (afirmando que el hecho de que las partes no tengan igual poder de negociación no hace
} 
El sector judicial, al igual que el legislativo, no siempre ha sido favorable al arbitraje. En particular, los jueces han desestimulado este método alternativo de solución de controversias de dos maneras. En primer lugar, el Consejo de Estado, así no lo haya hecho de manera consistente, en ocasiones ha anulado laudos arbitrales basándose en una amplia interpretación de las causales de nulidad, ya fueran las que establecía la antigua legislación (artículo 163 del Decreto 1818 de 1998) o las actuales (artículo 41 de la Ley 1563 de 2012), con lo cual el recurso termina volviéndose una instancia en la que se revisan de nuevo los méritos, contrario a la voluntad de las partes de un pacto arbitral ${ }^{77}$. El propio Consejo de Estado también ha afirmado que la nulidad puede declararse de oficio, a pesar de que la ley no consagra expresamente esta posibilidad y de que ello podría ir en contra de la voluntad de las partes ${ }^{78}$.

En segundo lugar, la Corte Constitucional ha limitado el arbitraje al afirmar que las partes no pueden pactar que los árbitros no motiven el fallo. ${ }^{79} \mathrm{Si}$ dichas partes así lo quieren, en aras de que el proceso sea más expedito y confiando en los árbitros que ellos mismos han elegido, no hay razones para que se les niegue esta posibilidad. Pero el gran problema de la Corte Constitucional con relación al arbitraje es la acción de tutela contra laudos o contra recursos de anulación, que atenta contra las características de celeridad, única instancia y seguridad jurídica que son inherentes al arbitraje ${ }^{80}$. Es por ello que este autor considera que, si las partes así lo pactan libremente, tal acción no debería proceder. ${ }^{81}$ En efecto, si las partes han preferido el arbitraje a la justicia ordinaria y han escogido a árbitros expertos es porque quieren solucionar el conflicto de manera rápida y porque confían en que quienes administren justicia van a proteger sus derechos fundamentales ${ }^{82}$. En tales casos, una acción de tutela implica cambiar un tribunal de arbitramento de tres árbitros, elegidos por las partes, por tres

por sí sola anulable una cláusula arbitral, ni tampoco el hecho de que se haya pactado a Chicago como sede. Sin embargo, la Corte sí consideró abusivo haber pactado que el arbitraje se rigiera por las normas de la Cámara de Comercio Internacional de París, ya que tal procedimiento era excesivamente costoso para el consumidor).

77 Véase, e.g., Sentencias del Consejo de Estado de agosto 9, 2012, CP.: Mauricio Fajardo, exp. 11001032600020120001300 (43.045), y de febrero 18, 2010, CP.: Enrique Gil, exp. 11001-03-26-000-2009-00058-00(37004). Véase generalmente, Gaviria, supra nota 54.

78 Véase, e.g., Sentencias del Consejo de Estado del 1 de agosto de 2002, Expediente 21.041 y del 10 de junio de 2009. Véase generalmente Cárdenas, Juan Pablo, Estatuto Arbitral Colombiano, Bogotá, Legis, 2013, p. 255.

79 Véase Cárdenas, Juan Pablo, Estatuto Arbitral Colombiano, Bogotá, Legis, 2013, p. 290.

80 Véase generalmente Gaviria, supra nota 54, p. 259.

81 Véase $i d$.

82 Véase $i d$. 
magistrados elegidos por el Congreso de la República que, además, suelen ser menos expertos que aquellos en el tema discutido.

Con todo, teniendo en cuenta que la jurisprudencia constitucional ha sido clara en afirmar que la tutela sí procede contra laudos arbitrales, esta es una realidad que se debe tener en cuenta ${ }^{83}$. Pero, por lo menos, sí se debería limitar el alcance de tal acción de tutela contra laudos arbitrales. Lamentablemente, esto no es lo que ha sucedido, especialmente en tratándose de controversias multimillonarias donde los representantes legales de las partes que perdieron el proceso arbitral, en su función de maximizar el patrimonio de sus accionistas (o de minimizar sus pérdidas) ${ }^{84}$, otorgan el mandato a sus abogados de presentar una acción de tutela que, no pocas veces y dada la cuantía y magnitud del caso, es seleccionada para revisión por la Corte Constitucional, la cual muchas veces termina revisando todos los méritos del caso $^{85}$.

83 Véase, e.g., Corte Constitucional, sentencia T-058 de 2009, MP. J. Araújo. Algunas otras sentencias de la Corte Constitucional que ratifican la procedencia de la acción de tutela contra laudos arbitrales son la T-057 de 1995, T-299 de 1996, SU-600 de 1999, T-121 de 2002, T-1089 de 2002, T-800 de 2004 y T-839 de 2005 y T-225 de 2010. En esta última se afirmó que "las reglas de procedencia y viabilidad de la acción de tutela cuando ella se dirige contra una providencia judicial son aplicables también a aquellos casos en los cuales la providencia cuestionada es un laudo arbitral o alguna otra decisión proferida dentro de un trámite arbitral. Y en la medida en que lo accesorio sigue la suerte de lo principal, la providencia que resuelve un recurso de anulación contra un laudo arbitral, también se somete al mismo análisis de procedibilidad." Véase generalmente Herrera, Hernando, La Impugnación de los Laudos Arbitrales, Bogotá, Legis, 2014, pp. 129-234. Obviamente, la acción de tutela contra un laudo arbitral debe cumplir los requisitos establecidos en el artículo 86 de la Constitución Política, en el Decreto Ley 2591 de 1991 y normas complementarias así como en la jurisprudencia. Estos requisitos, no obstante, no siempre son difíciles de cumplir (por ejemplo, cuando ya se agotó el recurso de nulidad o así esto no haya sucedido, dado que tal recurso tiene otros fines, no hay otro mecanismo de defensa mientras que si el litigio es de gran importancia para el actor, este podrá sufrir un perjuicio irremediable en caso de tener que cumplir el laudo arbitral). Véase $i d$., p. 156. Esta situación se agrava aún más teniendo en cuenta que la tutela contra un laudo puede ser incoada ante cualquier juez (por ejemplo, la tutela contra un laudo sobre temas especializados de telecomunicaciones podría ser admitida por un juez penal). Véase $i d ., p$ 215 ("Tanto el proceso arbitral como el recurso de anulación son susceptibles de tutela"). Véase generalmente artículo 23 de la Ley 222 de 1995.

85 Véase, e.g., Corte Constitucional, sentencia T-058 de 2009, MP. J. Araújo. T-225 de 2010. Afortunadamente, y aunque ello no justifica su uso, en ocasiones una Corte, mediante la acción de tutela corrige un error o ataque de otra Corte contra el arbitraje. Tal fue el caso de la Sentencia T-511 de 2011 que revocó la decisión del Consejo de Estado anulando un laudo proferido en el proceso entre Unión Temporal Mavig - Deprocon y el Fondo de Desarrollo Local de San Cristóbal de la Secretaría de Educación Distrital alegando que en el pacto arbitral no se observaba una decisión inequívoca, clara y vinculante 
Afortunadamente, no siempre las altas cortes colombianas han sido contrarias al arbitraje. Es de resaltar, por ejemplo, como desde hace más de un lustro la Corte Suprema de Justicia restringió el concepto de orden público internacional como causal para negar el exequatur de un laudo extranjero, limitando este a los valores fundamentales del derecho colombiano ${ }^{86}$.

\section{Conclusiones}

Este artículo es una crítica al nuevo gravamen sobre laudos arbitrales de contenido económico con base en tres argumentos. Para empezar, se explicó como este tributo atenta contra los principios de equidad tributaria, progresividad y acceso a la justicia. Acto seguido, se indicaron las razones por las cuales, independientemente de la contradicción entre las nuevas normas y la Carta magna colombiana, el tributo es inconveniente, tanto desde el punto de vista procesal, al ponerle trabas a un mecanismo alternativo de solución de controversias que ha demostrado ser eficiente, como desde la perspectiva tributaria, al gravar sumas de dinero que no representan un ingreso o, cuando sí lo son, al gravar un lucro cesante que ya está sometido al impuesto sobre la renta. En tercer lugar, el artículo explicó como este nuevo tributo es un ataque más, y posiblemente no el último, contra un mecanismo alternativo de solución de controversias que ha demostrado ser eficiente. Es de esperar que dicho ataque se conteste con todas las armas jurídicas posibles para que pronto tal gravamen se elimine de nuestra legislación, ya sea por decisión de la Corte Constitucional o del Congreso de la República, lo que ocurra primero.

\section{Referencias bibliográficas}

\section{Normas:}

Constitución Política de Colombia.

Código Civil.

Código de Comercio (Decreto Ley 410 de 1971).

Ley 1819 de 2016.

Ley 1739 de 2014.

Ley 1653 de 2013.

Ley 1607 de 2012.

de someter las diferencias a arbitraje. La Corte dijo que el Consejo de Estado había incurrido en error sustantivo al exigir una claridad y precisión mayor a la necesaria en el pacto arbitral, violando el derecho fundamental de acceso a la justicia. Véase también Herrera, supra nota 83, p. 210.

86 Véase Corte Suprema de Justicia, Sala. Civil, julio 27, 2011, MP. Ruth Marina Díaz, Expediente 11001-0203-000-2007-01956-00. 
Ley 1564 de 2012 (Código General del Proceso).

Ley 1563 de 2012 (Estatuto Arbitral Colombiano).

Ley 1480 de 2011 (Estatuto del Consumidor).

Ley 1394 de 2010.

Ley 1285 de 2009.

Ley 270 de 1996.

Ley 222 de 1995.

Decreto Ley 1818 de 1998.

Decreto Ley 111 de 1996 (Estatuto Orgánico del Presupuesto).

Decreto Ley 2591 de 1991.

Decreto Ley 624 de 1989 (Estatuto Tributario).

Decreto Único Reglamentario 1069 de 2015.

Decreto Reglamentario 1829 de 2013.

Acuerdo No. PSAA16-10554 del Consejo Superior de la Judicatura.

\section{Normas de otros países:}

Federal Arbitration Act (Estados Unidos).

\section{Sentencias de la Corte Constitucional:}

C-657 de 2015.

C-169 de 2014.

C-368 de 2011.

C-713 de 2008.

T-511 de 2011.

T-225 de 2010.

T-058 de 2009.

T-839 de 2005.

T-800 de 2004.

$\mathrm{T}-1089$ de 2002.

T-121 de 2002.

T-057 de 1995.

T-299 de 1996.

SU-600 de 1999.

\section{Sentencias de la Corte Suprema de Justicia:}

Sentencia de la Sala. Civil, julio 27, 2011, MP. Ruth Marina Díaz, Expediente 110010203-000-2007-01956-00.

\section{Sentencias del Consejo de Estado:}

Sentencia de agosto 9, 2012, CP. Mauricio Fajardo, exp. 11001032600020120001300 (43.045).

Sentencia de febrero 18, 2010, CP. Enrique Gil, exp. 11001-03-26-000-2009-0005800(37004). 
Sentencia del 10 de junio de 2009.

Sentencia del 1 de agosto de 2002, Expediente 21.041.

\section{Jurisprudencia de otros países:}

Brower v. Gateway 2000, Inc. 676 N.Y.S.2d 569 (N.Y. App. Div. 1998) (Estados Unidos).

\section{Libros:}

Cárdenas, Juan Pablo, Estatuto Arbitral Colombiano, Bogotá, Legis, 2013.

Gaillard, Emmanuel y Savage, John, Nueva York, Kluwer Law International, 1999.

Gaviria, Juan Antonio, El Problema del Hold-up en el Derecho de Contratos (Colombia, México y Estados Unidos), Editorial Porrúa, Ciudad de México, 2015.

Herrera, Hernando, La Impugnación de los Laudos Arbitrales, Bogotá, Legis, 2014Mankiw, N. Gregory, Principles of Economics, Edición 7, Nueva York, SouthWestern College Publishers, 2014.

Posner, Richard, Economic Analysis of Law, Octava edición, Nueva York, Wolters Kluwer Law \& Business, 2014.

Samuelson, Paul y Nordhaus, William, Economics, Edición 19, Nueva York, McGraw-Hill Education, 2009.

\section{Capítulos de libro:}

Silva Romero, Eduardo, De la calificación del arbitraje de internacional en el Estatuto de Arbitraje Nacional e Internacional colombiano, en Estatuto Arbitral Colombiano, Bogotá D.C., Legis, 2013.

\section{Artículos de revista:}

Gaviria, Juan Antonio, Comentarios sobre las nuevas normas colombianas en materia de arbitraje internacional, Revista de Derecho Privado, Universidad Externado de Colombia, pp. 259-81, Número 24 (2013).

\section{Páginas de Internet:}

Diccionario de la Real Academia Española de la Lengua, http://www.rae.es

Doing Business, Banco Mundial, http://www.doingbusiness.org

Portafolio, https://www.portafoliio.co/

Richard M. Langworth, https://richardlangworth.com/

YouTube, https://www.youtube.com/results?search_query=analisis+economico+del+derecho+alfredo+bullard+ 